\title{
Codificar para recriar: a busca do "Punctum"
}

\section{Renato Ferracini*}

Acredito que um dos trabalhos mais difíceis para o ator seja o de descobrir mecanismos corpóreos concretos para que ele possa recriar, no momento do Estado Cênico ${ }^{1}$, uma ação física em estado intensivo trabalhada em qualquer treinamento. Essa dificuldade faz com que a grande maioria das ações "expressivas", em qualquer treinamento, esteja nesse ambiente "não aproveitável", ambiente mecânico e dos clichês pessoais do corpo cotidiano. Mas existem momentos, nesses treinamentos, nos quais ações físicas orgânicas e estados corpóreos "vivos" ocorrem, justamente quando essa "expressão" corpórea mergulha em um campo de intensividade, foge dos clichês pessoais e redimensiona as ações que o corpo cotidiano realiza, jogando-o no caminho da construção de um corpo-subjétil|2. Mas justamente nesse momento de criação acontece uma segunda grande dificuldade: ou nós atores vivenciamos esse estado ou ação e pela repetição de sua ocorrência - se acontecer - acabamos adquirindo naturalmente os mecanismos para sua retomada; ou tentamos encontrar, forçar, estudar mecanismos corpóreos para uma posterior retomada de uma ação física ou estado. Acredito que nem seja preciso dizer que muitas e muitas ações e estados que entram nessa zona de intensividade são irremediavelmente perdidos pela nossa incapacidade de retomá-los e recriá-los posteriormente.

Podemos pensar que o ator, quando entra nesse estado intensivo, zona virtual, gera linhas de fuga e desterritorializações do macro Plano de Organização no qual seu corpo se insere e ao mesmo tempo introjeta essas linhas de fuga em formalizações musculares espaço/temporais. Durante esses últimos treze anos de trabalho prático no LUME acabei percebendo que, para que fosse possível uma retomada desses estados intensivos, eu deveria tentar contrair essa ação global em micro elementos que seriam como pontos musculares de retomada enquanto recriação dessas mesmas ações físicas no Estado Cênico. Procedendo dessa forma eu acabava adquirindo, para cada ação física, ou micro densidades musculares, ou micro articulações espaço/temporais, ou micro impulsos, ou mesmo imagens e sensações, ou

* Renato Ferracini, Doutor em multimeios (UNICAMP), é ator- pesquisador-colaborador integrante do LUME - Núcleo Interdisciplinar de Pesquisas Teatrais - UNICAMP. 
seja, pontos musculares específicos e contraídos que, quando ativados, me remetiam às ações físicas e matrizes $^{3}$, sendo possível sua retomada e recriação posterior. Todos esses elementos, independentes entre si, podiam ser contraídos em conjunto ou em partes, ou seja, uma ação física poderia conter apenas uma microarticulação de quadril como único ponto de retomada/recriação, enquanto outra possuiria dois micro impulsos e uma micro articulação que deveriam ser ativados em conjunto para que a recriação da ação e/ou da matriz fosse possível. A criação desses "pontos" era trabalhada de duas formas: ou através de uma percepção de repetição dessas mesmas ações, ou através de uma pesquisa e busca ativa, corpórea. Esses pontos musculares eram como "portas" de entrada para esse estado intensivo, que, quando ativados se expandiam e recriavam a ação física ou o estado, tanto em sua materialidade quanto em sua "vida" e organicidade, gerando tanto o estado atual recriado desse estado (físico e muscular) como o próprio estado virtual da ação enquanto intensividade. Tomando minha experiência pessoal de recriação de ação como uma possível experiência válida, posso dizer que, para que essas ações realmente expressivas (intensivas, orgânicas, "vivas") encontradas e pressionadas no treinamento sejam passíveis de serem recriadas, devo encontrar nelas mesmas contrações, pontos de ativação para a recriação da própria ação física no momento do ato artístico. A esses pontos de ativação corpóreos ou vocais chamarei Punctum.

O conceito de Punctum, aqui, é emprestado de Roland Barthes, principalmente da obra A Câmara Clara (1984). É utilizado por Barthes para nomear um "detalhe" na foto que chama a atenção daquele que olha. Punctum, enquanto o que me punge, o que me toca, o que afeta. Claro que Barthes coloca esse conceito enquanto recepção de um olhar na foto, um detalhe expansivo e metonímico que leva o receptor da foto para estados outros, um estado-em-arte da foto. Esse conceito de Punctum, em Barthes, está relacionado ao conceito de Studium. Segundo Barthes:

Muitas fotos, infelizmente, permanecem inertes diante de meu olhar. Mas mesmo entre as que têm alguma existência a meus olhos, a maioria provoca em mim apenas um interesse geral e, se assim posso dizer, polido: nelas nenhum Punctum: agradam-me ou desagradam-me sem me pungir: estão investidas somente de studim [...]. O Studium é o campo muito vasto do desejo indolente, do interesse diversificado, do gosto inconseqüente: gosto / não gosto (1984: 47)

Para o ator, o conceito de Studium de Barthes poderia estar vinculado ao terreno da mecanicidade, dos clichês, da fisicidade. Mas podemos reutilizar o conceito de Punctum para entendermos melhor a questão da recriação de 
ações físicas. Portanto, redimensiono aqui esse conceito na relação do ator para com ele mesmo. O que chamo de Punctum físico é, muitas vezes, um conjunto de pequenos detalhes da ação, mas são esses detalhes que interessam enquanto caráter potencialmente expansivo e metonímico do Punctum na ação física a ser recriada a posteriori. Metonímico no sentido de que esse detalhe muscular contém, em potência e em estado virtual, o todo da ação e que esse detalhe pode mobilizar esse mesmo todo, em um processo de atualização, ou seja, de recriação da ação. Como diz Barthes: por mais fulgurante que seja, o Punctum tem, mais ou menos virtualmente, uma força de expansão. Essa força é principalmente metonímica (1984: 73). A retomada de uma ação física, ou seja, sua recriação, é possível através da ativação de um Punctum físico que é potencialmente expansivo e metonímico, ou em outras palavras, a possibilidade da recriação da ação física no Estado Cênico é possível através da ativação de pequenos detalhes corpóreos e ou vocais, sejam eles micro ou macro densidades musculares, micro ou macro ritmos e planos no tempo/espaço que mobilizam o todo, recriando a ação física. Punctum, portanto, é uma porta de entrada corpórea para a recriação da ação física, e sendo uma recriação lança o corpo cotidiano do ator em um estado outro, um estado de corpo-subjétil, corpo-em-arte, corpo-em-jogo. Através desses detalhes físicos que recriam a ação física em sua intensividade, o ator é capaz de reviver, ou melhor, recriar sua ação física no momento da atuação. Esses pontos musculares (Punctum) são pontos musculares em estado metonímico e contraídos que possibilitam um processo de atualização - e, portanto recriações - de ações físicas vivenciadas anteriormente e que se encontram virtualizadas no corpo enquanto memória. Assim, o que chamamos, no LUME, de matriz codificada é, na verdade, um corpo varrido por pontos que podem ser ativados no momento da atuação enquanto ação a ser recriada nela mesma.

Não somos, de forma alguma, arrebatados por esse pontos, pelo Punctum, mas existe claramente uma zona de controle dentro da própria expansão do Punctum, dentro da própria recriação da matriz. Em outras palavras, ao mesmo tempo em que recriamos, sabemos que estamos recriando, por mais arrebatadora que essa recriação seja, tanto para nós atores como para os espectadores. Criamos, portanto, uma zona de jogo. E não confundamos esse saber com uma questão intelectual. É o próprio corpo-subjétil, em estado uno, englobado com o próprio estado mental, que "sabe" que está criando com todas as forças. Dessa forma ele mergulha em um estado intensivo de trabalho, de jogo, de correlações, de zonas de vizinhança, mas ao mesmo tempo, "sabe" que está nesse estado, pode ativar outro Punctum, pode sair desse estado e entrar em outros, pode se abrir para afetações, pode afetar, desviar o foco, brincar com o espaço, "improvisar" e mesmo brincar com o próprio Punctum e matrizes. Uma zona co-existente de criação e jogo, de 
controle e completo mergulho dentro dessa zona de intensividades.

O Punctum não é exclusivo de matrizes enquanto ações físicas codificadas. Eles se estendem a todo o trabalho do ator, mesmo os pré-expressivos. Sabemos, por experiência, que a repetição de elementos técnicos e energéticos treinados geram vivências físicas, energéticas e intensivas que são armazenadas em estado virtual no corpo cotidiano. Essas mesmas vivências físicas, energéticas e intensivas, como ações físicas expressivas que são trabalhadas cotidianamente, também acaba gerando o Punctum ou conjunto deles por repetição dos elementos pré-expressivos trabalhados e que podem ser ativados a posteriori, recriando esse "estado" virtual previamente armazenado.

Sobre esse "estado" frisemos um ponto: relembremos que o Punctum, segundo Barthes, possui um caráter expansivo e metonímico. E já verificamos que para o trabalho de ator, ele também possui essas características, mas, dentro do trabalho de ator essas características são, mais ou menos, independentes. Assim, ao gerarmos o Punctum ou conjunto deles em trabalhos energéticos e/ou técnicos, podemos ativá-los, posteriormente em seu caráter metonímico, mas não expansivo, ou, em outras palavras, podemos ativar o Punctum sem que ele se expanda no espaço e recrie a ação física formalizada. Quando ativamos o Punctum sem utilizar seu caráter expansivo, criamos o que chamamos, internamente, no LUME, de um estado corpóreo no qual ativamos as intenções de todos os trabalhos pré-expressivos, gerando uma dinâmica corpórea em uma suposta inatividade. Assim podemos ativar o Punctum, ou conjunto deles, de vivências extremas do energético, e de elementos pré-expressivos dos trabalhos realizados nos treinamentos técnicos, jogando o corpo em uma espécie de estado corpóreo extracotidiano, ou ainda, o que dá no mesmo, um estado dilatado, ou estado intensivo, sem qualquer ação expandida. Para ser mais preciso, não é que, no Punctum, suas características metonímicas e expansivas sejam completamente independentes entre si: na realidade, ativando o Punctum de uma matriz ativamos também seu caráter expansivo, mas esse último, de certa forma, é controlável pelo ator. Ativando o Punctum, ou conjunto deles, de uma ação-física, ou matriz, ou vivência do trabalho energético, ou elementos pré-expressivos do treinamento técnico, ativamos, necessariamente, as articulações e os impulsos desses trabalhos, mas os tapamos, os contraímos, os "seguramos", criando uma (in)tenção desses elementos, gerando micro articulações, micro impulsos no espaço, mas que são, de certa forma, concretos para o ator. Assim, o que chamamos de estado é um Punctum, ou conjunto deles, ativados, tendo seu lado expansivo controlado, contraído.

É justamente esse controle que coloca o corpo em um estado de ação na inação, inação essa aparente, pois o esforço em controlar e manter o Punctum sem seu caráter expansivo faz com que tenhamos toda uma relação não 
cotidiana com nossa musculatura, o que dá a sensação interna, para o ator, de uma dilatação corpórea e para o espectador, de fora, de uma presença não natural do ator. Criamos um estado em intenção que prepara o corpo cotidiano para um mergulho em uma zona intensiva. Em um jargão interno dentro do LUME, quando ativamos somente o Punctum sem seu caráter expansivo referentes a todo o trabalho técnico e energético trabalhado no passado - sejam vivências do treinamento energético e/ou mesmo princípios pré-expressivos de trabalho existente no presente de forma contraída e em estado virtual no corpo cotidiano - dizemos que "entramos em trabalho". "Entrar em trabalho" significa, então, atualizar o Punctum, ou conjunto deles, contraídos em estado virtual de todo o trabalho pré-expressivo do ator contraindo, controlando sua expansão. Obviamente, como as vivências e o estado virtual de todo o trabalho é acumulativo, quanto mais tempo de treinamento pré-expressivo um ator tenha, mais Punctum, ou conjunto deles, em estado virtual ele terá e, portanto mais "portas" de entrada haverá. Mas tomemos cuidado: a palavra "mais", aqui, não pode ser lida apenas de modo quantitativo, ou ainda em relação a uma possível causa-efeito simplista, mas deve ser lida de forma qualitativa. O Punctum pré-expressivo pode ser mais e mais "afirmado", pontuado, sublinhado, redescoberto durante o trabalho cotidiano pré-expressivo do ator. E quanto mais sublinhado o Punctum, maior a força de sua expansão quando ativado. Assim, também, mais potencializado o estado para o qual o Punctum, ou conjunto deles, remete o corpo. Não porque o Punctum, em si, remeta o corpo cotidiano de forma mais potencializada a esse estado, mas porque a força que será necessária para não expandir um Punctum será maior, já que o próprio Punctum estando mais sublinhado, possui uma força potencial e virtual de atualização maior.

Dessa forma, quando recrio uma matriz estarei ativando, necessariamente, um conjunto em camadas de um Punctum ou vários deles, pois ao ativar o Punctum da matriz esse ativará, também, o Punctum de todo o trabalho pré-expressivo enquanto camada anterior de trabalho. O Punctum da matriz ativa o Punctum pré-expressivo formando uma rede que "liga", expande e transborda o corpo cotidiano, lançando-o à recriação de matrizes e estados corpóreos "dilatados", enfim, ao corpo-subjétil. Essa ativação em conjunto e em camadas acontece, pois quando uma matriz nasce, nosso corpo está "em trabalho", ou seja, o corpo está com o Punctum pré-expressivo, ou um conjunto deles, ativado. Dessa forma, quando codifico uma matriz corpórea, ou seja, quando encontro o Punctum capaz de recriar uma ação física trabalhada por mim em treinamento cotidiano ou em trabalhos pontuais - mimese corpórea, por exemplo - acabo trabalhando o Punctum, ou conjunto deles, dessas matrizes que são pontuados sobre o estado de trabalho, ou seja, sobre uma "camada" de Punctum pré-expressivo ativado. Portanto, toda ativação/recriação de uma matriz, já que sua pontuação/codificação 
foi assentada nesse estado de trabalho, será uma ativação também desse estado que se somará e se conectará à própria força intensiva da matriz. É por isso que as matrizes de um ator em sua recriação, enquanto vocabulário pré-expressivo de trabalho, são renovadas em sua força: quanto mais tempo o ator utiliza para realizar um trabalho pré-expressivo, tanto mais ele afirma o Punctum pré-expressivo. Quanto mais Punctum, ou conjunto deles, ele descobre e sublinha em seu trabalho, enfim, quanto mais treina, mais seu vocabulário também é sublinhado e afirmado, já que o "estado de trabalho" ativado pelo Punctum pré-expressivo e a própria matriz formam uma ação expressiva única, realizada em camadas que se diagonalizam e se retro-alimentam, renovando-se.

Mas também devemos trabalhar para manter o Punctum de uma ação/ matriz. O tempo ocioso desgasta, desbasta o Punctum de uma ação física. Nós, enquanto atores, sempre corremos esse perigo. Devemos, pois, retrabalhar nosso vocabulário de ações/matrizes, recriando-as em sala de trabalho, sublinhando e aprofundando seu Punctum. Claro que um Punctum muito sublinhado será mais difícil de ser desgastado e perdido, mas ações e matrizes recentemente descobertas devem ser trabalhadas para que seu Punctum, ou conjunto deles, seja cada vez mais acentuado e sublinhado. Quando perdemos o Punctum de uma matriz, a "porta" de entrada para sua recriação, não significa que não conseguimos reproduzi-la no tempo/espaço, mas significa que essa reprodução passa a ser mecânica; a matriz não possui mais um campo de intensividades e a musculatura apenas repete os movimentos previamente assimilados da matriz e isso não interessa em absoluto. O Punctum ativado, ao mesmo tempo em que lança a musculatura para uma ação no tempo/espaço, lança também essa mesma ação em uma zona intensiva, de criação. Por isso recriamos uma ação física, nunca a repetimos. E o Punctum é a chave inicial dessa recriação.

Pela própria característica do Punctum em ser metonímico e expansivo e esses elementos serem mais ou menos independentes, toda matriz terá, então, um estado - quando o Punctum é ativado com um controle de sua expansão - e uma ação - quando o Punctum é finalmente expandido e a recriação da ação física acontece no tempo/espaço. Também a graduação espaço/temporal entre esse estado e a ação total pode ser controlada. Podemos ter apenas o estado da matriz, enquanto ação numa aparente inação, ou recriá-la apenas com suas ações muito reduzidas, pouco reduzidas e mesmo com ações expandidas, maiores que a ação codificada propriamente dita. Podemos, inclusive, omitir certos movimentos, realizar variações de ritmos e dinâmicas e mesmo tentar "colar" outras ações/movimentos por sobre o estado da matriz. A essa possibilidade de brincar com a fisicidade da matriz dei o nome de variação de fisicidade. Assim, para cada matriz teremos uma 
gama quase infinita de possibilidades de trabalho espaço/temporal, pois para cada matriz poderemos criar submatrizes e variações dela mesma no espaço/tempo.

Temos, portanto, dois universos que podem ser percebidos, apesar de não serem absolutamente independentes: ao estado que o Punctum ativado sem expansão recria, podemos chamar de corporeidade e a possibilidade de toda a variação formal e mecânica sobre esse estado podemos chamar de fisicidade. Podemos dizer que o ator deveria aprender a manipular a fisicidade da ação sem nunca perder sua corporeidade. Esses conceitos diferenciados de corporeidade e fisicidade foram propostos inicialmente por Luís Otávio Burnier:

A corporeidade é a maneira como as energias potenciais se corporificam, é a transformação destas energias em músculo, ou seja, em variações diversas de tensão. Esta transformação de energias potenciais em músculo é o que origina a ação física (BURNIER, 2001: 75).

Já a fisicidade corresponde à parte mecânica pela qual se operacionaliza uma ação física no tempo/espaço. Da fisicidade fazem parte o movimento, a relação desse movimento com o tempo/espaço, enfim, elementos que correspondem à ordem mecânica da ação física. Na definição do próprio Luís Otávio Burnier:

Por fisicidade, entendo a maneira como o corpo age e faz, como ele intervém no espaço e no tempo, o seu dinamorritmo. A corporeidade é mais do que a pura fisicidade de uma ação. Ela, em relação ao indivíduo atuante, antecede a fisicidade... [...] a corporeidade está, pois, entre a fisicidade e as energias potenciais do ator. Ela pode ser considerada como a primeira resultante física do processo de dinamização das distintas qualidades de energias que se encontram em estado potencial. Está muito próxima do que podemos chamar de "qualidades de vibração". Ela significa a primeira etapa deste processo de corporificação das qualidades de vibração, ao passo que a fisicidade significa a etapa final deste processo (BURNIER, 2001: 75).

Concordo com Luís Otávio, mas devemos tomar cuidado, pois, na verdade, esses conceitos se imbricam e não devem ser pensados separadamente: a fisicidade, enquanto mecânica da ação, suporta sua própria corporeidade enquanto potência intensiva dessa mesma ação/matriz. Em outras palavras, seria impossível gerar um estado, uma corporeidade, sem 
uma formalização anterior que, quando suprimida em seu caráter expansivo no ativar do Punctum dessa matriz, gera esse estado, gera a corporeidade da ação. Mas a própria corporeidade suporta fisicidades espaço/temporais que são mergulhadas no campo intensivo da corporeidade, numa espiral que engloba ambos os conceitos, recriando a matriz e gerando submatrizes. A corporeidade seria o estado da matriz; um Punctum ativado sem seu caráter expansivo, jogando o corpo cotidiano em uma zona intensiva. A fisicidade mergulha nessa zona e é absorvida por esse plano (corporeidade). A corporeidade nada mais é que o estado "anterior" da matriz, intensivo, mas real e coexistente, da ação física no tempo/espaço (fisicidade).

\section{Notas}

${ }^{1}$ Chamo de Estado Cênico o momento específico em que o ator se encontra na ação de atuação juntamente com o público e com todos os elementos que compõe a cena. Prefiro usar o termo "Estado Cênico" ao geralmente usado "Estado de Representação" ou ainda "Representação" pois acredito que o conceito de "representação", mesmo não sendo usado nesse artigo dentro de um território filosófico, pode gerar distorções dentro da conceituação do trabalho do ator, já que esse termo possui uma carga conceitual histórica densa e pela massa enorme dessa carga pressionará, certamente, o conceito teatral de "representação" que, dentro do território teatral, pode ser simplesmente pensado enquanto atuação, ação de atuar. Se rebatido ao seu conceito filosófico, devemos esclarecer que o ator não se coloca no lugar de algo, não representa algo. Ele não é uma imagem imperfeita colocada no lugar de uma outra imagem. Ele não é, portanto, uma segunda presença que está no lugar de uma primeira presença que não está ali, seja de uma suposta personagem, seja de uma imagem, seja de uma estado emotivo. $\mathrm{Na}$ verdade, o ator cria uma ação poética recriada a cada instante no momento em que atua, age em cena. Ele não se coloca no lugar de, mas cria um espaço único, uma ação única que gera um acontecimento também único.

${ }^{2}$ CORPO-SUBJÉTIL: um corpo-em-arte não pode ser conceituado como uma ponta de um dualismo, mas como um corpo integrado e vetorial em relação ao corpo com comportamento cotidiano. Chamei, então, esse corpo integrado expandido como corpo-em-arte, esse corpo inserido no Estado Cênico de corpo-subjétil. Subjétil seria, segundo Derrida, retomando uma suposta palavra inventada por Artaud, a palavra ou a coisa [que] pode tomar o lugar do sujeito ou do objeto, não é nem um, nem outro (Derrida e Bergstein, 1998: 23). Um subjétil não é um sujeito, muito menos o subjetivo, não é tampouco o objeto, mas exatamente o quê e a questão do "quê" guarda um sentido no que concerne ao que está entre isto ou aquilo [...] (1998: 38 - grifo meu). Outra questão é que essa palavra subjétil pode, por semelhança, ser aproximada da palavra projétil, o que nos leva à imagem de projeção, para 
fora, um projétil que, lançado para fora, atinge o outro e, como ficará mais claro adiante, também se auto atinge. Essa aproximação pode ser realizada já que "subjétil" é uma palavra intraduzível, pois, como foi supostamente inventada por Artaud, não existe tradução possível em outras línguas. Corposubjétil: um corpo em Estado Cênico, um corpo em arte, pois encontra-se nesse "entre" objetividade - subjetividade, pois não é nem um nem outro exatamente, mas os perpassa pelo meio, englobando as duas pontas da polaridade e todos os outros pontos que passem por essas linhas opostas. Ele não é um ponto ou outro, linha ou outra, mas uma diagonal que atravessa esses pólos abstratos e todos os pontos e linhas "entre". Em segundo lugar porque esse "entre" do subjétil, agindo como um projétil, lança-se para fora para agrupar e incluir o outro, em um movimento que deveria ser natural no trabalho do ator. Portanto, o corpo-subjétil engloba e diagonaliza um espaço "entre" polaridades que se completam e uma ação que lança esse espaço "entre" para fora, numa relação dinâmica. intrinsecamente, o terreno do trabalho do ator.

${ }^{3}$ Dentro do âmbito de trabalho do LUME, podemos dizer que uma ação física e/ou vocal orgânica, pesquisada e codificada por um ator e que dinamiza seus campos intensivos potenciais, é chamada de "matriz". Se procurarmos no dicionário Aurélio, encontraremos algumas das razões para essa palavra ter sido utilizada para definir uma ação física orgânica: "Matriz: lugar de onde se gera ou se cria; aquilo que é fonte, origem, base; útero". Assim, a matriz é entendida como o material inicial, principal e primordial; é como a fonte de material do ator, à qual ele poderá recorrer, sempre que desejar, para a construção de qualquer trabalho cênico. A matriz é a própria ação física/vocal, viva e orgânica, codificada que pode ser recriada no momento do Estado Cênico. Dessa forma, cada ator possui um conjunto de matrizes, que se torna seu vocabulário vivo de comunicação cênica - seu vocabulário expressivo.

\section{Bibliografia}

BARTHES, ROLAND. A Câmara Clara. Trad. Júlio Castañon Guimarães. Rio de Janeiro : Editora Nova Fronteira, 1984.

BURNIER, LUÍS OTÁVIO. A arte de ator: da técnica à representação. Campinas. Editora da Unicamp, 2001.DERRIDA, JACQUES e BERGSTEIN, LENA. Enlouquecer o Subjéctil. Trad. Geraldo Gerson de Souza. São Paulo. Fundação Editora da UNESP. 1998. 